\title{
LICENCIAMENTO AMBIENTAL E ESTUDOS ARQUEOLÓGICO: A POSSIBILIDADE DE FIRMAR TERMO DE AJUSTAMENTO DE CONDUTA NA HIPÓTESE DO DESCUMPRIMENTO DO RITO
}

Mariana Barbosa Cirne ${ }^{1}$

\section{RESUMO}

Este artigo defende que no caso de descumprimento do prazo dos estudos arqueológicos no âmbito do licenciamento ambiental é cabível firmar termo de ajustamento de conduta para regularizar o procedimento administrativo. Por meio de revisão bibliográfica e jurisprudencial, pretende-se demonstrar que diante do problema reiterado do descumprimento dos estudos prévios arqueológicos, uma possível solução jurídica dada ao Iphan é definir, por meio de um termo de ajustamento de conduta, a fixação de reparação civil como maneira de concretizar o que corresponderia às condicionantes do licenciamento.

Palavras-chave: licenciamento ambiental; arqueologia; termo de ajustamento de conduta; rito; condicionante.

\section{ENVIRONMENTAL LICENSING AND ARCHAEOLOGICAL STUDIES: THE POSSIBILITY OF SIGNING A TERM OF ADJUSTMENT OF CONDUCT IN THE HYPOTHESIS OF BREACH OF PROCEDURE}

\begin{abstract}
This article argues that in the case of noncompliance with the term of the archaeological studies in the ambit of environmental licensing it is possible to sign a term of adjustment of conduct to regularize the administrative procedure. The paper did a bibliographical and jurisprudential review. It is intended to demonstrate that, faced with the repeated problem of non-compliance with previous archaeological studies, a possible legal solution given to Iphan is to define, by means of a behavior adjustment term, civil that would correspond to the licensing constraints.
\end{abstract}

Keywords: environmental licensing; archeology; conduct adjustment Term; rite; conditioning.

\section{INTRODUÇÃO}

Este artigo defende que no caso de descumprimento do prazo dos estudos arqueológicos no âmbito do licenciamento ambiental é cabível firmar termo de ajustamento de conduta como meio para regularizar o procedimento administrativo.

\footnotetext{
${ }^{1}$ Doutoranda e Mestre em Direito, Estado e Constituição (UnB), especialista em Direito Público (UnP) e em Processo Civil (IDP), e bacharela em Direito (UFPE). Procuradora Federal (AGU) e Professora de Direito Ambiental e de Difusos e Coletivos (UNICEUB). E-mail: marianabcirne@gmail.com 
A pesquisa se justifica por ser feitas no tema ambiental mais controvertido do momento: o licenciamento ambiental. Os antropocentristas ${ }^{2}$, assim como os desenvolvimentistas, veem o licenciamento ambiental como um entrave ao desenvolvimento brasileiro. Prova disso são as a Proposta de Emenda Constitucional (PEC) n. 65, de 14 de dezembro de $2012^{3}$, e o Projeto de Lei do Senado n. 654, de $2015^{4}$, de autoria do Senador Romero Jucá, em trâmite no Congresso Nacional. As duas propostas reduzem prazos de análise ou inviabilizam a suspensão das licenças como maneira de tornar o licenciamento mais efetivo.

Por outro lado, há um enorme questionamento - judicial e político - pela sociedade civil e pelo Ministério Público ${ }^{5}$ quanto às demandas sociais a serem atendidas necessariamente no bojo do licenciamento ambiental e de que maneira esse pleito merece ser atendido. Para os preservacionistas ${ }^{6}$, e para quem é biocentrista ${ }^{7}$ ou ecocentrista, o componente socioambiental precisa ser ampliado no bojo do licenciamento ambiental ${ }^{8}$. Este trabalho se pauta, dentro dessa discussão, no componente cultural, especialmente no impacto ambiental a ser evitado por estudos sobre o patrimônio arqueológico brasileiro 9 .

Apesar da divergência, o licenciamento ambiental ainda é considerado, hoje, como o instrumento que melhor concretiza o princípio da prevenção ${ }^{10}$ dentro do direito

\footnotetext{
${ }^{2}$ Para uma discussão sobre as correntes éticas do Direito, ver: COELHO, 2014.

${ }^{3}$ A PEC n. 65/2012 está em audiência pública e tem como objetivo acrescentar o $§ 7^{\circ}$ ao art. 225 da Constituição Federal para assegurar a continuidade de obra pública. "Dispõe que a apresentação do estudo prévio de impacto ambiental importa autorização para a execução da obra, que não poderá ser suspensa ou cancelada pelas mesmas razões a não ser em face de fato superveniente." BRASIL. Proposta de Emenda Constitucional no 65, de 2012 (do Senado Federal). PEC n. 65/2012. Disponível em: <https://www25.senado.leg.br/web/atividade/materias//materia/109736>. Acesso em 2 mai. 2016.

${ }^{4}$ O PLS n. 654/2015: "Dispõe sobre o procedimento de licenciamento ambiental especial para empreendimentos de infraestrutura considerados estratégicos e de interesse nacional.”. BRASIL. Projeto de Lei no 654, de 2015 (do Senado Federal). PLS n. 654/2015. Disponível em: <http://www25.senado.leg.br/web/atividade/materias//materia/123372>. Acesso em: 22 abr. 2016.

${ }^{5}$ Conforme atuação do Ministério Público Federal, com destaque para a $4^{\circ}$ Câmara de Coordenação e Revisão do Ministério Público Federal. Disponível em: 〈http://mpf.mp.br/atuacao-tematica/ccr4〉. Acesso em: Acesso em: 28.10.2016.

${ }^{6}$ Paulo de Bessa Antunes (2010, p. 11) resume o preservacionismo como uma corrente que se distancia dos movimentos sociais e das lutas políticas, que não acredita na possibilidade de envolvimento das populações tradicionais na conservação da biodiversidade. Segundo o autor, para essa corrente doutrinária, as populações tradicionais - e os pobres de uma maneira geral - são uma ameaça à conservação ambiental, contudo, esta não são as premissas adotadas neste trabalho. Prefere-se, no caso, trabalhar com as premissas de Paulo Afonso Leme Machado (2015) e Carlos Marés (2002), ao englobarem neste conceito a questão cultural.

${ }^{7}$ Ver: SARLET; FENSTERSEIFER, 2014.

${ }^{8}$ Nesse sentido, ver as pautas do ISA, O Instituto Socioambiental, uma organização da sociedade civil brasileira, sem fins lucrativos, fundada em 1994, "para propor soluções de forma integrada a questões sociais e ambientais com foco central na defesa de bens e direitos sociais, coletivos e difusos relativos ao meio ambiente, ao patrimônio cultural, aos direitos humanos e dos povos." Disponível em: <https://www.socioambiental.org/ptbr/o-isa>. Acesso em: 28.10.2016.

${ }^{9}$ Cf. Lei n ${ }^{\circ} 3.924$, de 26 de julho de 1961 (BRASIL) e Portarias IPHAN no 07/1988 e 230/2002.

${ }^{10}$ Conforme explica Érica Bechara (2015), o objetivo deste princípio é o de direcionar as normas jurídicas e as políticas públicas para se firmarem no sentido de prevenir as lesões ao meio ambiente, antecipando os danos que possam ser causados e assim, tentar impedi-los.
} 
ambiental, sendo indispensável para garantir um meio ambiente equilibrado, valor fundamental trazido pelo art. 225 da Constituição de $1988^{11}$. Exatamente por isso, o presente artigo é relevante, pois demonstra que este instrumento, apesar das críticas, ainda merece debates e aperfeiçoamentos. Na hipótese de descumprimento de seus prazos, cabe uma reflexão sobre as maneiras de regularizar esse procedimento, evitando, mitigando e compensando os danos ao patrimônio arqueológico em questão.

Diante desse quadro, a pergunta que desafia este artigo é a seguinte: $o$ descumprimento dos estudos prévios arqueológicos do licenciamento ambiental pode ensejar a responsabilidade civil? O termo de ajustamento de conduta pode ser um instrumento hábil a regularizar esse procedimento?

Para responder esse questionamento, será explicado na primeira parte do artigo em que consiste o licenciamento ambiental, seu conceito, e a sua relação com a avaliação de impactos ambientais, com destaque para os estudos quanto ao patrimônio arqueológico. De posse desses conceitos, serão demonstrados os malefícios do descumprimento da antecipação dos estudos. Em seguida, será tratado o termo de ajustamento de conduta como instrumento que pode ensejar uma tentativa de compatibilizar as demandas ambientais com a celeridade que o licenciamento ambiental precisa ter na sua aplicação, não deixando, contudo, de sancionar aqueles que descumprem os seus princípios.

Este artigo não pretende esgotar um tema complexo como licenciamento ambiental com impacto em patrimônio arqueológico, mas sim apresentar uma das facetas de suas controvérsias (o descumprimento do estudo prévio) e em seguida trazer reflexões sobre os efeitos de um termo de ajustamento de conduta para regularizar o processo administrativo. Parece ser um primeiro passo para um debate que precisa ser desenvolvido no âmbito do Direito Ambiental.

Apresentados os seus principais pontos, passa-se, então, a trilhar o itinerário estabelecido.

\section{O LICENCIAMENTO AMBIENTAL E OS ESTUDOS ARQUEOLÓGICOS}

Nos termos do art. 20, X, da Constituição de $1988^{12}$, os sítios arqueológicos são bens da união e para que se efetivem atividades ou empreendimentos que os impactem, são

11 BRASIL. Constituição Federal, de 5 de outubro de 1988. Disponível em: <http://www.planalto.gov.br/ccivil_03/Constituicao/Constituicao.htm>. Acesso em: 21 abr. 2016.

${ }^{12}$ Cf. "Art. 20. São bens da União: (...)X - as cavidades naturais subterrâneas e os sítios arqueológicos e préhistóricos;” (BRASIL, 1088). 
indispensáveis estudos, precedidos de autorização a ser concedida pelo Instituto do Patrimônio Histórico e Artístico Nacional - Iphan.

Nos termos dos artigos $8^{\circ}$ e $9^{\circ}$ da Lei $n^{\circ} 3.924$, de $1961^{13}$, a autorização para realizar esses estudos deve ser direcionada ao Iphan, podendo ser atendidos, caso os requisitos sejam satisfeitos. Como estabelecido na lei, tais estudos precisam ser realizados impreterivelmente antes da implantação do empreendimento ou da atividade licenciada. Apesar disso, infelizmente, existe uma cultura de descaso quanto ao patrimônio arqueológico no Brasil. Em regra, ocorre o descumprimento do empreendedor quanto ao momento de iniciar a implementação da atividade, em frontal descumprimento da lei (CALDARELLI, 2007). Apenas após a conclusão do empreendimento ou atividade são realizados os estudos, o que gera duas possíveis consequências: a) a identificação de danos ao patrimônio arqueológico e a fixação de medidas compensatórias ou b) a inexistência de danos ao patrimônio arqueológico. Apesar de o descumprimento dos prazos merecer todas as sanções possíveis, o seu reiterado descumprimento impõe a busca, no Direito, de possíveis soluções para esta situação.

Cabe ressaltar que tais estudos são, em regra, demandados no bojo de licenciamento ambiental. Isso parece relevante para as conclusões dente artigo.

O licenciamento ambiental é um dos mais importantes instrumentos da Política Nacional do Meio Ambiente ${ }^{14}$.Nos termos do arts. $9^{\circ}$, inciso IV, e $10^{\circ}$ da Lei $n^{\circ}$ 6.938/81, deve ser exigido previamente na construção, instalação, ampliação e funcionamento de estabelecimentos e atividades utilizadoras de recursos ambientais ${ }^{15}$ de efetivo ou potencial capacidade poluidora, ou capazes de causar degradação sob qualquer forma, levando em conta as disposições legais e regulamentares e as normas técnicas aplicáveis ao caso. O

\footnotetext{
${ }^{13}$ Cf. "Art $8^{\circ} \mathrm{O}$ direito de realizar escavações para fins arqueológicos, em terras de domínio público ou particular, constitui-se mediante permissão do Govêrno da União, através da Diretoria do Patrimônio Histórico e Artístico Nacional, ficando obrigado a respeitá-lo o proprietário ou possuidor do solo.

Art $9^{\circ} \mathrm{O}$ pedido de permissão deve ser dirigido à Diretoria do Patrimônio Histórico e Artístico Nacional, acompanhado de indicação exata do local, do vulto e da duração aproximada dos trabalhos a serem executados, da prova de idoneidade técnico-científica e financeira do requerente e do nome do responsável pela realização dos trabalhos."

${ }^{14}$ Cf. Art. 9. (...) IV. o licenciamento e a revisão de atividades efetiva ou potencialmente poluidoras; BRASIL. Lei $\mathrm{n}^{\circ}$ 6.938, de 31 de agosto de 1981. Disponível em: 〈http://www.planalto.gov.br/ccivil_03/leis/L6938.htm>. Acesso em: 2 abr. 2018. Há ainda o conceito de licenciamento ambiental mais recente previsto no art. 2, I, da Lei Complementar $\mathrm{n}^{\circ}$ 140/2011: Art. $2^{\circ}$ Para os fins desta Lei Complementar, consideram-se: I - licenciamento ambiental: o procedimento administrativo destinado a licenciar atividades ou empreendimentos utilizadores de recursos ambientais, efetiva ou potencialmente poluidores ou capazes, sob qualquer forma, de causar degradação ambiental; Cf. BRASIL. Lei complementar $n^{o}$ 140, de 8 de dezembro de 2011. Disponível em: <http://www.planalto.gov.br/ccivil_03/leis/LCP/Lcp140.htm>. Acesso em: 2 abr. 2018.

${ }^{15}$ A Lei determina em seu art. $3^{\circ}$, inciso $\mathrm{V}$, como recursos ambientais "a atmosfera, as águas interiores, superficiais e subterrâneas, os estuários, o mar territorial, o solo, o subsolo, os elementos da biosfera, a fauna e a flora” BRASIL. Lei $\mathrm{n}^{\circ}$ 6.938, de 31 de agosto de 1981. Disponível em: <http://www.planalto.gov.br/ccivil_03/leis/L6938.htm>. Acesso em: 21 abr. 2016.
} 
licenciamento ambiental é um típico instrumento de prevenção de danos ambientais. É através dele que o órgão ambiental licenciador verifica a dimensão dos impactos que a implantação de um empreendimento causaria.

A Constituição Federal não fez referência direta ao licenciamento ambiental no seu texto, contudo, não há como negar que este instrumento funciona como concretização dos valores ambientais constitucionais trazidos em seu artigo 225 (FARIAS, 2013, p. 32). Isso porque o licenciamento ambiental se relaciona com todos os incisos do $\$ 1^{\circ}$ do art. 225 , que estabelecem responsabilidades ao Poder Público para assegurar a efetividade do direito ao meio ambiente equilibrado ${ }^{16}$. Por exemplo, quando o inciso I fala em "preservar e restaurar os processos ecológicos essenciais e prover o manejo ecológico das espécies e ecossistemas" isso significa que, salvo adotadas as medidas de prevenção cabíveis, as atividades econômicas que ameaçam os processos ecológicos essenciais e os ecossistemas não deverão receber a licença ambiental (TRENNEPOHL; TRENNEPOHL, 2010, p. 37). Entretanto, o instrumento constitucional mais diretamente interligado ao licenciamento ambiental está previsto no inciso IV do $\S 1^{\circ}$ do art. 225. É o Estudo Prévio de Impacto Ambiental - EPIA, que exige "na forma da lei, para instalação de obra ou atividade potencialmente causadora de significativa degradação do meio ambiente, estudo prévio de impacto ambiental, a que se dará publicidade" ${ }^{, 17}$. Portanto, a obrigatoriedade do EPIA é uma imposição constitucional que se desenvolve no bojo do licenciamento ambiental.

Segundo Nelson Bugalho (1999), algumas considerações podem ser extraídas deste dispositivo constitucional sobre o EPIA. A primeira delas é a de que o estudo prévio de impacto ambiental deve ser exigido pelo Poder Público, devendo ser regulamentado por normas infraconstitucionais ${ }^{18}$. A segunda observação é a de que o termo "prévio" empregado exige que o estudo seja realizado antes da instalação da obra ou atividade potencialmente

\footnotetext{
${ }^{16}$ Para Kurt e Terence Trennepohl (2010, p. 37), o licenciamento ambiental pode ser definindo como o processo de concordância do Poder Público com as obras ou atividades condicionadas à aprovação do Estado.

17 BRASIL. Constituição Federal, de 5 de outubro de 1988 . Disponível em: <http://www.planalto.gov.br/ccivil_03/Constituicao/Constituicao.htm>. Acesso em: 21 abr. 2016.

${ }^{18}$ Nesse sentido, o Supremo Tribunal Federal fixou entendimento de que somente lei federal poderia excluir as hipóteses de incidência deste preceito, vide, acórdão de 2001, acerca do julgamento da ADI 1.086/SC: AGRAVO REGIMENTAL NO RECURSO EXTRAORDINÁRIO. CONSTITUCIONAL. AMBIENTAL. IMPOSSIBILIDADE DE LEI ESTADUAL DISPENSAR ESTUDO PRÉVIO DE IMPACTO AMBIENTAL. AGRAVO IMPROVIDO. I - O Plenário desta Corte, ao julgar a ADI 1.086/SC, Rel. Min. Ilmar Galvão, assentou que a previsão, por norma estadual, de dispensa ao estudo de impacto ambiental viola o art. 225 , § $1^{\circ}$, IV, da Constituição Federal. II - Agravo regimental improvido. BRASIL. Supremo Tribunal Federal. Ação Direta de Inconstitucionalidade. ADI 1.086/SC. Tribunal Pleno. Relator: Min. Ilmar Galvão. Brasília, 10 de agosto de 2001. Disponível em: <http://www.stf.jus.br/portal/jurisprudencia/listarJurisprudencia.asp?s1=\%28ADI\%24\%2ESCLA\%2E+E+1086 \%2ENUME\%2E\%29+OU+\%28ADI\%2EACMS\%2E+ADJ2+1086\%2EACMS\%2E\%29\&base=baseAcordaos\& url=http://tinyurl.com/b26trn9>. Acesso em: 21 abr. 2016.
} 
poluidora, não podendo ser concomitante nem posterior a elas ${ }^{19}$. Em terceiro lugar, o EPIA sempre será exigido nos casos em que a obra ou atividade possa causar degradação expressiva. Em resumo, o estudo prévio de impacto ambiental é pressuposto para o licenciamento de "construção, instalação, ampliação, reforma e funcionamento de estabelecimentos, obras ou quaisquer atividades potencialmente degradadoras do meio ambiente".

Antes desta previsão constitucional, a Lei no 6.938/81 já trazia a Avaliação de Impactos Ambientais - AIA como um dos instrumentos da Política Nacional de Meio Ambiente $^{20}$. Contudo, foi somente com sua regulamentação específica pela Resolução Conama $n^{\circ}$ 01/86 que este instrumento realmente passou a ter aplicabilidade (SÁNCHEZ, 2006). A Resolução definiu tanto as diretrizes gerais para elaboração do estudo (art. $5^{\circ}$ ), mas também que este estudo deveria ser elaborado por equipe multidisciplinar independente do proponente do projeto (art. $7^{\circ}$ ). $\mathrm{O}$ artigo $2^{\circ}$ desta Resolução ${ }^{21}$ também trouxe uma lista de atividades sujeitas ao EIA-RIMA como condição para o licenciamento ambiental. Ou seja, ficou estabelecido que dentro do processo de avaliação de impacto ambiental, o empreendedor deveria apresentar dois documentos, preparados por equipe técnica multidisciplinar independente, o Estudo de Impacto Ambiental - EIA e o Relatório de Impacto Ambiental - RIMA, este sendo o documento destinado à informação e consulta pública, devendo, portanto, ser escrito de forma simplificada, trazendo as conclusões presentes no EIA.

Posteriormente, a Resolução CONAMA n 237/97 definiu os Estudos Ambientais em seu artigo $1^{\circ}$, como:

III - (...) todos e quaisquer estudos relativos aos aspectos ambientais relacionados à localização, instalação, operação e ampliação de uma atividade ou empreendimento, apresentado como subsídio para a análise da licença requerida, tais como: relatório ambiental, plano e projeto de controle ambiental, relatório ambiental preliminar, diagnóstico ambiental, plano de manejo, plano de recuperação de área degradada e análise preliminar de risco. ${ }^{22}$

\footnotetext{
${ }^{19}$ Esse entendimento, contudo, não extingue a possibilidade de complementação desses estudos, a fim de estabelecer novas condicionantes ou medidas mitigadoras, conforme a dinamicidade do licenciamento ambiental, prevista no art. 19 da Resolução CONAMA 237.

20 BRASIL. Lei $\mathrm{n}^{\mathrm{o}} 6.938$, de 31 de agosto de 1981. Disponível em: <http://www.planalto.gov.br/ccivil_03/leis/L6938.htm〉. Acesso em: 21 abr. 2016.

${ }^{21}$ Cf. "Artigo $2^{\circ}$ - Dependerá de elaboração de estudo de impacto ambiental e respectivo relatório de impacto ambiental - RIMA, a serem submetidos à aprovação do órgão estadual competente, e do IBAMA em caráter supletivo, o licenciamento de atividades modificadoras do meio ambiente, tais como:" BRASIL. Resolução CONAMA $\mathrm{n}^{\mathrm{o}}$ 001, de 23 de janeiro de 1986. Disponível em: <http://www.mma.gov.br/port/conama/res/res86/res0186.html>. Acesso em: 21 abr. 2016.

22 BRASIL. Resolução CONAMA $\mathrm{n}^{\mathbf{0}}$ 237, de 22 de dezembro de 1997. Disponível em: http://www.mma.gov.br/port/conama/legislacao/CONAMA_RES_CONS_1997_237.pdf. Acesso em: 21 abr. 2016.
} 
O Estudo de Impacto Ambiental é, portanto, um meio de atuação preventiva do Estado, avaliando as dimensões da interferência que um projeto (obra/atividade) possa vir a causar nos atributos de quaisquer dos elementos que compõem o meio ambiente (BUGALHO, 1999). Segundo Sandra Cureau (2012), o principal objetivo desse instrumento, dentro do licenciamento ambiental, é dar à administração pública "uma base sólida de informação para a tomada de decisão quanto à autorização para o prosseguimento do projeto, sopesando os impactos sobre o meio físico, biótico e antrópico com os seus benefícios sociais".

Dessa forma, no Brasil, o processo de avaliação de impacto ambiental, na forma do EIA-RIMA, é indispensável ao licenciamento ambiental ${ }^{23}$, devendo ser apresentado para toda e qualquer atividade potencialmente poluidora que necessite de uma licença para funcionar (SANCHES, 2006). Logo, o impacto ao patrimônio arqueológico precisa estar inserido neste conceito de estudos.

O Supremo Tribunal Federal, na ADI-MC 1505-2 ${ }^{24}$ (BRASIL, 2004), sob relatoria do Ministro Francisco Rezek, já reconheceu a complexidade e tecnicidade do Estudo de Impacto Ambiental. A Constituição do Estado do Espírito Santo, em seu art. 187 §3º, pretendia submeter a apreciação do relatório de impacto ambiental de projetos de grande porte à Comissão Permanente e Específica da Assembleia Legislativa, de modo a impedir a participação de pessoas físicas ou jurídicas que atuaram na sua elaboração. O posicionamento do STF firmado neste caso foi o de que "o preceito viola, flagrante e sob diversos aspectos, dispositivos e princípios constitucionais que subjugam o limite do poder constituinte dos estados-membros". (BRASIL,2004, p. 2) A inconstitucionalidade se pauta no fato de que decisão seria eminentemente de cunho político, retirando-se o caráter técnico da decisão. $\mathrm{O}$ estudo de impacto ambiental, como um dos instrumentos mais complexos e técnicos da política nacional do meio ambiente, "não pode ter sua aprovação sujeita a exame político de uma comissão parlamentar, sob pena de desvirtuar-se inteiramente a fundamentação técnica essencial à proteção ambiental”. (BRASIL, 2004, p.9)

\footnotetext{
${ }^{23}$ Nem todo licenciamento necessita necessariamente da realização de um Estudo de Impacto Ambiental. As hipóteses de cabimento do EIA são trazidas de forma exemplificativa no art. $2^{\circ}$ da Resolução CONAMA n ${ }^{\circ}$ 01/86. BRASIL. Resolução CONAMA $n^{\circ}$ 001, de 23 de janeiro de 1986. Disponível em: <http://www.mma.gov.br/port/conama/res/res86/res0186.html>. Acesso em: 2 abr. 2018.

${ }^{24}$ Cf. "Essas exigências decorrem do fato de configurar-se o estudo de impacto ambiental, como diz Paulo de Bessa Antunes, num dos instrumentos mais complexos e técnicos dentre aqueles utilizados pela política nacional do meio ambiente, que integra o processo de licenciamento ambiental o que, como se sabe, é um ato administrativo formal e vinculado.” BRASIL. Supremo Tribunal Federal. Ação Direta de Inconstitucionalidade Medida Liminar. ADI-MC n. 1505-2/ES. Tribunal Pleno. 2004. Disponível em:< http://redir.stf.jus.br/paginadorpub/paginador.jsp?docTP=AC\&docID=347100> Acesso em: 25 jan. 2018, p. 9 .
} 
Neste mesmo sentido há decisão do STF, na ADI 3252-6 (BRASIL, 2005, p. 2$)^{25}$, sob relatoria do Ministro Gilmar Mendes, que também concluiu que "as autorizações ambientais são típicas atividades do Poder Executivo e assim são tratadas pela Lei 6.938/81”.

Em ambos os casos citados, o Supremo Tribunal Federal ao reconhecer a ofensa ao princípio da independência e harmonia entre os Poderes, reconheceu como atividade típica do Poder Executivo a avaliação dos impactos ambientais, deixando clara a função essencial e eminentemente técnica dos estudos de impacto ambiental.

Trazendo os elementos do licenciamento ambiental para esse debate, deve-se dizer que antes da expedição das licenças ambientais, o empreendedor deve realizar os estudos, o que demanda a obediência aos trâmites dos artigos $8^{\circ}$ e $9^{\circ}$ da Lei no 3.924, de 1961. Isso porque, é da natureza do licenciamento ambiental a antecipação dos possíveis danos que serão causados, para que se possa então avaliar formas de evitar, mitigar ou compensá-los.

Erika Bechara (2015) explica que o licenciamento ambiental é um típico instrumento de prevenção de danos ambientais. É através dele que o órgão ambiental licenciador verifica a dimensão dos impactos que a implantação de um empreendimento causaria. As considerações feitas no processo condicionam o exercício da atividade ao atendimento de inúmeros requisitos aptos a eliminarem ou reduzirem o impacto ambiental negativo, chamados de condicionantes do licenciamento ambiental.

No mesmo sentido, André Krull identifica que o papel mitigador dos impactos do licenciamento ambiental se dá através de suas condicionantes. Ou seja, as condicionantes praticamente se confundem com a função do licenciamento, que é a de garantir proteção adequada ao meio ambiente diante de atividades de efetivo ou potencial capacidade degradadora.

As condicionantes, portanto, são exigências feitas ao longo do processo de licenciamento durante as três fases de emissão das licenças, com o objetivo de evitar, mitigar ou compensar os impactos de um determinado empreendimento ou atividade que possa vim a causar prejuízo ao meio ambiente. Em outras palavras, são compromissos firmados entre o empreendedor e o órgão licenciador a fim de cumprir a finalidade do licenciamento ambiental, que é a de garantir que os desenvolvimentos econômico, social e ambiental sejam

${ }^{25}$ BRASIL. Supremo Tribunal Federal. Ação Direta de Inconstitucionalidade Medida Cautelar. ADI-MC n. 3.252-6/RO. Tribunal Pleno. 2005. Disponível em:< http://redir.stf.jus.br/paginadorpub/paginador.jsp?docTP=TP\&docID=335110> Acesso em: 25 jan. 2018. 
compatibilizados $^{26}$. Entender isso se faz imperioso para entender o ilícito em questão na hipótese do patrimônio arqueológico.

Isso porque, em regra, o órgão licenciador emite as licenças ambientais sem exigir os necessários estudos arqueológico, apesar de serem expressamente exigidos pela lei (CALDARELLI, 2007). Após construído o empreendimento, o empreendedor buscará regularizar a sua situação junto ao órgão licenciador. Apresentará, na hipótese, o EIA-RIMA que muitas vezes poderá concluir que não houve danos ao patrimônio arqueológico. Cria-se, com isso, uma loteria para aqueles que preterem os estudos prévios arqueológicos. Caso o EIA-RIMA não identifique danos ao patrimônio arqueológico, pretensamente o empreendedor não seria lesado. Exatamente para evitar essa postura que desconsidera o ilícito do descumprimento do estudo prévio que uma possível saída aparece no reconhecimento de que houve o descumprimento do rito do licenciamento ambiental, no qual deveriam ter sido feitos tempestivamente os estudos.

Diante dessa situação, o termo de ajuste de conduta - TAC pode ser uma interessante resposta para ajustar a conduta ilícita de não seguir o rito administrativo do licenciamento ambiental, na hipótese em que o empreendimento já estava em operação, mas que eventuais danos ao patrimônio arqueológico não foram identificados após a realização dos estudos. Não haveria aqui o dano, mas permanece presente o ilícito que ensejaria a reparação civil.

Como já explicado, os estudos ambientais - o que inclui os arqueológicos - não deve possuir a função de justificar a implantação de um empreendimento ou atividade, mas sim de apontar os possíveis prejuízos ambientais, sociais e culturais que aquela atividade acarretará numa determinada área, com base no princípio da prevenção, a fim de auxiliar o órgão ambiental competente a identificar quais medidas mitigadoras serão necessárias ser implantadas (TRENNEPOHL; TRENNEPOHL, 2010, p. 37). Conforme estabelecido na Portaria IPHAN $n^{0} 1 / 88$, a solicitação precisa ser prévia ${ }^{27}$. O empreendedor não pode se valer de seu ilícito - implantação prematura do empreendimento sem a realização dos estudos cabendo, então, a transformação dessa obrigação prévia de estudo em uma medida

\footnotetext{
${ }^{26}$ Cf. Brasil. Tribunal de Contas da União. Cartilha de licenciamento ambiental / Tribunal de Contas da União; com colaboração do Instituto Brasileiro do Meio Ambiente e dos Recursos Naturais Renováveis - 2.ed. Brasília: TCU, 4a Secretaria de Controle Externo, 2007, p. 19.

${ }^{27} \mathrm{Cf}$. "Artigo $1^{\circ}$ - Estabelecer os procedimentos necessários à comunicação prévia, às permissões e às autorizações para pesquisas e escavações arqueológicas em sítios arqueológicos previstas na lei $\mathrm{n}^{\circ} 3.924$, de 26 de julho de 1961"
} 
compensatória ao patrimônio arqueológico. Mesmo que o EIA-RIMA depois demonstre que não houve prejuízo ao patrimônio arqueológico.

Sabe-se que o direito ambiental é dinâmico e variável e o licenciamento ambiental, enquanto processo concretizador desse direito, acompanha sua dinamicidade, podendo suas condições serem alteradas a qualquer momento, sofrendo "retificações, convalidações e calibrações necessárias de acordo com os impactos ambientais detectados" (BIM, 2015, p. 24). Em havendo ilícito por parte do empreendedor na fase dos estudos, cabe o estabelecimento de outra medida para sanar tal irregularidade. O Supremo Tribunal Federal, em decisão do Ministro Sepúlveda Pertence, em 2006, já reconheceu essa dinamicidade do licenciamento, ao esclarecer que “(...) os vícios e as falhas acaso detectados no seu conteúdo [EIA/RIMA] poderão e deverão ser corrigidos no decorrer do processo de licenciamento ambiental". 28

Ora, a quebra de uma importante fase do licenciamento ambiental - a realização dos estudos prévios - merece estabelecer medidas compensatórias no intuito de regularizar esse procedimento. Isso porque não pode o empreendedor ganhar com a sua ilegalidade, ao desobedecer o rito administrativo do licenciamento ambiental.

Incontroversa a ilicitude do ato praticado pelo empreendedor, ao não solicitar os estudos prévio, cabem, portanto, pensar em medidas compensatórias, pois não há como se definir aqui medidas preventivas (o empreendimento já está em operação) ou mitigadoras (o estudo ainda será realizado, mesmo que de maneira prejudicada).

Impõe-se, dessa forma, o estabelecimento de compensação, o que pode ser realizado, como se tratar em seguida, por meio de TAC, com o intuito de regularizar a atuação do empreendedor. Caso o Iphan fosse o órgão licenciador, poderia fazer isso por meio da modificação das condicionantes. Mas, como a autarquia não é, pode realizar essa solução para regularizar o procedimento administrativo do licenciamento por meio de Termo de Ajustamento de Conduta.

\section{O TAC COMO INSTRUMENTO HÁBIL A REGULARIZAR A QUEBRA DE RITO DO LICENCIAMENTO QUANTO AO ESTUDO ARQUEOLÓGICO}

O Termo de Ajustamento de Conduta (TAC) tem como principal finalidade a reparação de um dano causado ou a prevenção/eliminação de um ilícito. No caso deste artigo,

\footnotetext{
${ }^{28}$ Cf. STF, ACO-MC 876/BA, rel. Min. Sepúlveda Pertence, j. Em 18/12/2006, DJU 01/02/3007, p.148, RTJ 200/01/242. No mesmo sentido: TRF da $4^{a}$ Região, $3^{\text {a }}$ T., v.u., AC 2006.71.003801-8/RS, rel. Des. Fed. Carlos Eduardo Thompson Flores Lenz, j. em 13/10/2009.
} 
busca-se apresentá-lo como instrumento hábil à eliminação de um ilícito. Ou seja, constitui pressuposto para a celebração de um termo de ajustamento de conduta a existência de um comportamento que necessite ser ajustado às obrigações legais. Sobre o tema, Geisa Paganini de Mio, Edward Ferreira Filho e José Roberto Campos (2006, p. 43) explicam que o TAC, “é um instrumento legal destinado a colher do causador do dano ao meio ambiente, entre outros interesses difusos e coletivos, um título executivo de obrigação de fazer e não fazer, mediante o qual, o responsável pelo dano assume o dever de adequar a sua conduta às exigências legais, sob pena de sanções fixadas no próprio termo."

José dos Santos Carvalho Filho (2005) defende que através do TAC deve-se procurar restaurar integralmente a legalidade. Tanto é assim que o define como "o ato jurídico pelo qual a pessoa, reconhecendo implicitamente que sua conduta ofende interesse difuso e coletivo, assume o compromisso de eliminar a ofensa através de adequação de seu comportamento às exigências legais." O autor complementa, explicando que o TAC "é admissível, em casos especiais, que nele se preveja obrigação de indenizar, seja isoladamente, seja em conjunto com obrigação de fazer ou não fazer. Semelhante obrigação, contudo, só tem legitimidade para constar do título se a indenização tiver como objetivo a reparação de danos causados a algum dos interesses transindividuais.” Teori Zavascki (2017, p. 147-148) também admite o TAC para substituir uma execução específica por outra providência que leve a resultado equivalente. Não se abre mão, no caso, do direito material, mas sim se ajusta a conduta para a legalidade. O art. $2^{\circ}$, I, da Portaria IPHAN 159/2016 permite como objeto do TAC "adequar conduta irregular às disposições legais em vigor" 29 . No caso, diante do descumprimento dos estudos prévios, o TAC permite a compensação por tal conduta irregular.

Portanto, a celebração de um termo de ajustamento de conduta pressupõe a existência ou a iminência de uma conduta em desconformidade com o ordenamento jurídico. Ou seja, não obstante, não haja a necessidade da configuração de dano ao patrimônio cultural, mostra-se imprescindível a caracterização de um ilícito presente ou futuro, para que haja conduta a ser ajustada.

As disposições contidas na Portaria-IPHAN n 07/1988, na Portaria-IPHAN no 230/2002 ou na Instrução Normativa $n^{\circ}$ 01/2015, e sobretudo na Lei $n^{\circ} 3.924 / 61$, permitem uma interpretação de que o descumprimento temporal dos estudos necessários ao

${ }^{29}$ Cf. “Art. 2 (...) I - Termo de Ajustamento de Conduta -TAC: instrumento elaborado, à luz do art. 5º $\S 6^{\circ}$, da Lei $\mathrm{n}^{\circ} 7.347$, de 24 de julho de 1985, com objetivo de reparar dano patrimonial e extrapatrimonial causado a um bem acautelado, adequar conduta irregular às disposições legais em vigor e evitar conduta ilícita iminente, caso haja fundado receio de que venha a se concretizar;" 
licenciamento para a constatação de possível dano ao patrimônio arqueológico - mesmo que não se confirme - configura-se a como uma ocorrência de ilícito a autorizar a celebração de termo de ajustamento de conduta no intuito de regularizar este procedimento.

O fundamento legal do TAC está previsto no art. $5^{\circ}, \S 6^{\circ}$, da Lei n. ${ }^{\circ} 7.347$, de 24 de julho de 1985, que disciplina a ação civil pública de responsabilidade por danos causados ao meio-ambiente, ao consumidor, a bens e direitos de valor artístico, estético, histórico, turístico e paisagístico ${ }^{30}$. Hugo Nigro Mazzilli (2009, p. 409) explica que as principais características do TAC são: a) ser tomado por termo por um dos órgãos públicos legitimados à ação civil pública; b) nele não existir concessões de direito material por parte do órgão público legitimado, mas sim o causador do dano assume uma obrigação de fazer ou não fazer (ajustamento de conduta às obrigações legais); c) dispensam-se testemunhas instrumentárias; d) dispensa-se a participação de advogados; e) não é colhido nem homologado em juízo; f) o órgão público legitimado pode tomar o compromisso de qualquer causador do dano, mesmo que este seja outro ente público (só não pode tomar compromisso de si mesmo);

g) é preciso prever o próprio título as cominações cabíveis, embora não necessariamente a imposição de multa; h) o título deve conter obrigação certa, quanto à sua existência, e determinada, quanto ao seu objeto, e ainda deve conter obrigação exigível. O compromisso assim constitui título executivo extrajudicial. No âmbito normativo, o TAC deve observar ainda o preconizado no art. $4^{\circ}$-A da Lei $n^{\circ} 9.469 / 1997^{31}$. No âmbito do Iphan, com o intuito de auxiliar os gestores nesta tarefa de formular TAC, foi editada a Portaria IPHAN nº 159/2016, a ser cumprida.

Ora, estes normativos endossam a possibilidade de firmar o TAC e com tal medida regularizar o procedimento por quebra dos ritos dos estudos. No caso, não houve concessões de direito material por parte do órgão público, mas sim o estabelecimento de compensação no bojo do licenciamento, como uma espécie de condicionante.

\footnotetext{
${ }^{30}$ Cf. "Art. $5^{\circ}(\ldots) \S 6^{\circ}$ - Os órgãos públicos legitimados poderão tomar dos interessados compromisso de ajustamento de sua conduta às exigências legais, mediante cominações, que terá eficácia de título executivo extrajudicial." Dispositivo vigente, conforme decisão do STJ: "A referência ao veto ao artigo 113, quando vetados os artigos $82, \S 3^{\circ}$, e 92 , parágrafo único, do CDC, não teve o condão de afetar a vigência do $\S 60$, do artigo 5 o, da Lei 7.374/85, com a redação dada pelo artigo 113, do CDC, pois inviável a existência de veto implícito.” (RESP 222.582/MG, Rel. Min. Milton Luiz Pereira, Primeira Turma, J. em 12.03.2002)

${ }^{31}$ Cf. "Art. 4o-A. O termo de ajustamento de conduta, para prevenir ou terminar litígios, nas hipóteses que envolvam interesse público da União, suas autarquias e fundações, firmado pela Advocacia-Geral da União, deverá conter: I - a descrição das obrigações assumidas; II - o prazo e o modo para o cumprimento das obrigações; III - a forma de fiscalização da sua observância; IV - os fundamentos de fato e de direito; e V - a previsão de multa ou de sanção administrativa, no caso de seu descumprimento. Parágrafo único. A AdvocaciaGeral da União poderá solicitar aos órgãos e entidades públicas federais manifestação sobre a viabilidade técnica, operacional e financeira das obrigações a serem assumidas em termo de ajustamento de conduta, cabendo ao Advogado-Geral da União a decisão final quanto à sua celebração.”
} 
Cabe, contudo, no termo de ajustamento de conduta estabelecer de que é a responsabilidade pelo ilícito, podendo esta ser imputada tanto a quem diretamente o causou quanto a terceiros, independentemente de terem contribuído para o ato lesivo. Registre-se, ainda, que a compensação por um ilícito deve ser diversa daquelas que constam no processo administrativo sobre o licenciamento ambiental. Isso porque são responsabilidades ambientais diversas $^{32}$. No caso do patrimônio arqueológico, a responsabilidade civil aparece como caminha especialmente interessante, visto que as infrações administrativas não se concretizam, pois os valores estabelecidos do Decreto Lei $n^{\circ} 25 / 37$, quando atualizados, mostram-se irrisórios. Ora, permanece, portanto, a responsabilidade civil e criminal, mas a administrativa, ao ser concretizada, demonstra-se inexequível.

Bem se vê, portanto, que a pretensão de sanar a ilicitude dos estudos prévios, por meio de TAC, pode cumprir o objetivo maior do licenciamento, que segundo Daniel Fink e Marcelo Dawalibi (2000), é conciliar o desenvolvimento econômico com a preservação do meio ambiente, não limitando a liberdade empresarial, mas evitando que o exercício ilimitado de um direito atinja outros, também fundamentais.

O conceito atual de proteção ambiental, nesse sentido, tem como premissa a tríplice perspectiva do desenvolvimento sustentável, buscando a compatibilização do desenvolvimento socioeconômico com a preservação da qualidade do meio ambiente e do equilíbrio ecológico.

Cabe reconhecer que o licenciamento precisa ser célere, sem, contudo, perder o seu componente cultural. Nesse sentido, Paulo Affonso Leme Machado (2015) explica que a função do estudo ambiental não deve ser de influenciar as decisões estatais apenas para as questões ambientais em detrimento de eventuais ganhos econômicos e sociais do projeto, mas criar um balanço entre esses fatores. O TAC, no caso dos estudos do patrimônio arqueológico que depois evidencie a ausência de dano, parece um importante caminho para incentivar o cumprimento dos estudos prévios.

Dessa forma, a fim de garantir que o licenciamento abarque todos os fatores socioeconômicos e ambientais atingidos pelo empreendimento ou atividade, é necessário que o órgão ambiental competente trabalhe conjuntamente com outros órgãos especializados, ponderando os diversos interesses envolvidos no processo, que dependem do caso concreto e da dinâmica social, e não apenas o meio ambiente natural. No caso do Iphan, por não ser o

\footnotetext{
${ }^{32} \mathrm{Cf}$. "art. 225. (...)§ $3^{\circ}$ As condutas e atividades consideradas lesivas ao meio ambiente sujeitarão os infratores, pessoas físicas ou jurídicas, a sanções penais e administrativas, independentemente da obrigação de reparar os danos causados."
} 
licenciador, o TAC parece cumprir o papel que as condicionantes poderiam realizar no bojo do licenciamento. Rose Mirian Hofmann (2016) endossa essa posição, ao explicar que: "todos os temas conservacionistas merecem, sim, espaço no licenciamento ambiental, mas de forma ponderada dentro de uma análise global”.

Dessa forma, é possível concluir que o TAC permite regularizar o procedimento do licenciamento ambiental, na hipótese de descumprimento dos prazos para os estudos prévios quanto aos impactos arqueológicos, garantindo, dessa forma o desenvolvimento sustentável. Incentivando, portanto, que os estudos sejam prévios, mesmo na hipótese do impacto ao patrimônio arqueológico não se materializar. Com tal medida, evita-se que o descumprimento dos estudos prévio não seja punido, garantindo, assim, maior celeridade e eficiência ao processo.

\section{CONCLUSÃO}

O presente artigo tratou sobre o instrumento mais controvertido do Direito Ambiental: o licenciamento ambiental, com destaque para os indispensáveis estudos arqueológicos a cargo do Iphan. Conforme apresentado, o licenciamento ambiental, enquanto instrumento concretizador do Direito Ambiental, não deve se limitar a proteger, mitigar e compensar apenas o meio ambiente natural, mas se estender ao meio cultural no qual o empreendimento está inserido.

O licenciamento ambiental é um processo que tem como objetivo a prevenção dos danos, uma vez que as condicionantes precisam ser pautadas em estudos prévios de impactos. Essas condicionantes, posteriormente, devem ser cumpridas pelo empreendedor, garantindose o desenvolvimento sustentável, o que exige o componente cultural. Infelizmente, tornou-se contumaz o desrespeito aos estudos prévios arqueológicos. O EIA-RIMA muitas vezes é apresentado após o empreendimento ou a atividade estar em execução e por vezes atesta que o patrimônio arqueológico não foi danificado. Contudo, mesmo nestes casos, permanece o descumprimento dos estudos prévios como ilícito do empreendedor.

Diante dessa realidade em que os estudos ocorrem a posteriori, parece indispensável propor formas de punir tal ilícito, regularizando tais procedimentos, o que parece possível por meio do TAC. Conclui-se que caso este não seja a via eleita, estaríamos incentivando a quebra de rito, visto que não caberá nenhuma sanção para a hipótese dos estudos concluírem que inexiste patrimônio arqueológico afetado.

Pode-se, com essa experiência, evidenciar um caminho para conjugar os princípios dos licenciamentos, com a eficiência que este instrumento demanda. 
O licenciamento ambiental, mesmo com suas fragilidades tem se comportado como um instrumento importante porque consegue prever, mesmo que em parte, impactos futuros causados por um empreendimento ou atividade, sendo possível impor mitigações a fim de reduzi-los. Mesmo que estes danos não se identifiquem, o TAC parece ser um caminho importante para regularizar o procedimento administrativo, como uma forma de condicionante, e com tal medida reparar o dano decorrer da ausência de previsibilidade. Desse modo, ao se buscar celeridade e dinamicidade no licenciamento, o objetivo não deve ser simplesmente acelerar o processo, mas sim, garantir uma análise eficaz dos danos ambientais gerados pelo empreendimento, sem comprometer sua viabilidade. Este artigo espera ser um primeiro passo em uma discussão que precisa ser desenvolvida.

\section{REFERÊNCIAS}

ANTUNES, Paulo Bessa. Direito Ambiental. 12a ed. Rio de Janeiro: Lumen Juris, 2010.

BECHARA, Erika. Uma contribuição ao aprimoramento do instituto da compensação ambiental previsto na lei 9.985/2000. Disponível em:

<http://www.dominiopublico.gov.br/download/teste/arqs/cp041032.pdf >. Acesso em 12 jun. 2015.

BENJAMIN, Antônio Herman. Direito Constitucional Ambiental Brasileiro. In: LEITE, José Rubens Morato; CANOTILHO, José Joaquim Gomes. (org.). Direito Constitucional Ambiental Brasileiro. $3^{\circ}$ ed. São Paulo: Saraiva, 2010

BIM, Eduardo Fortunato. Licenciamento Ambiental. $2^{\text {a }}$ edição. Rio de Janeiro: Lumen Juris, 2015.

BRASIL. Constituição Federal, de 5 de outubro de 1988. Disponível em: <http://www.planalto.gov.br/ccivil_03/Constituicao/Constituicao.htm>. Acesso em: 21 abr. 2017.

BRASIL. Lei $n^{\circ}$ 6.938, de 31 de agosto de 1981. Disponível em: <http://www.planalto.gov.br/ccivil_03/leis/L6938.htm>. Acesso em: 21 abr. 2016.

BRASIL. Lei complementar $n^{\circ}$ 140, de 8 de dezembro de 2011. Disponível em: <http://www.planalto.gov.br/ccivil_03/leis/LCP/Lcp140.htm>. Acesso em: 21 abr. 2016.

BRASIL. Projeto de Lei $n^{\circ}$ 654, de 2015b (do Senado Federal). PLS n. 654/2015. Disponível em: <http://www25.senado.leg.br/web/atividade/materias/-/materia/123372>. Acesso em: 6 abr. 2018.

BRASIL. Proposta de Emenda Constitucional no 65, de 2012 (do Senado Federal). PEC $n$. 65/2012. Disponível em: https://www25.senado.leg.br/web/atividade/materias//materia/109736. Acesso em 2 mar. 2018.

BRASIL. Resolução CONAMA no 001, de 23 de janeiro de 1986. Disponível em: 
<http://www.mma.gov.br/port/conama/res/res86/res0186.html>. Acesso em: 21 abr. 2016.

BRASIL. Resolução CONAMA $n^{\circ}$ 237, de 22 de dezembro de 1997. Disponível em: http://www.mma.gov.br/port/conama/legislacao/CONAMA_RES_CONS_1997_237.pdf. Acesso em: 21 abr. 2016.

BRASIL. Superior Tribunal de Justiça. RESP 222.582/MG, Rel. Min. Milton Luiz Pereira, Primeira Turma, J. em 12.03.2002.

BRASIL. Supremo Tribunal Federal. Ação Cível Originária. ACO-MC 876/BA. Terceira Turma. Relator: Min. Sepúlveda Pertence. Brasília, 18 de dezembro de 2006. Disponível em: <http://www.stf.jus.br/portal/processo/verProcessoAndamento.asp?incidente=2381836>. Acesso em: 9 abr. 2018.

BRASIL. Supremo Tribunal Federal. Ação Direta de Inconstitucionalidade Medida Liminar. ADI-MC n. 1505-2/ES. Tribunal Pleno. 2004. Disponível em:< http://redir.stf.jus.br/paginadorpub/paginador.jsp?docTP=AC\&docID=347100> Acesso em: 25 jan. 2018.

BRASIL. Supremo Tribunal Federal. Ação Direta de Inconstitucionalidade Medida Cautelar. ADI-MC n. 3.252-6/RO. Tribunal Pleno. 2005. Disponível em:< http://redir.stf.jus.br/paginadorpub/paginador.jsp?docTP=TP\&docID=335110> Acesso em: 25 jan. 2018.

BRASIL. Supremo Tribunal Federal. Ação Direta de Inconstitucionalidade. ADI 1.086/SC. Tribunal Pleno. Relator: Min. Ilmar Galvão. Brasília, 10 de agosto de 2001. Disponível em: <http://www.stf.jus.br/portal/jurisprudencia/listarJurisprudencia.asp?s1=\%28ADI\%24\%2ESC $\mathrm{LA} \% 2 \mathrm{E}+\mathrm{E}+1086 \% 2 \mathrm{ENUME} \% 2 \mathrm{E} \% 29+\mathrm{OU}+\% 28 \mathrm{ADI} \% 2 \mathrm{EACMS} \% 2 \mathrm{E}+\mathrm{ADJ} 2+1086 \% 2 \mathrm{EAC}$ MS\%2E\%29\&base=baseAcordaos\&url=http://tinyurl.com/b26trn9>. Acesso em: 2 abr. 2018.

BRASIL. Supremo Tribunal Federal. Mandado de Segurança. MS 22.164-0/SP. Tribunal Pleno. Relator: Min. Celso de Mello. Brasília, 30 de outubro de 1995. Disponível em: $<$ http://www.stf.jus.br/portal/jurisprudencia/listarJurisprudencia.asp?s1=\%28MS\%24\%2ESC $\mathrm{LA} \% 2 \mathrm{E}+\mathrm{E}+22164 \% 2 \mathrm{ENUME} \% 2 \mathrm{E} \% 29+\mathrm{OU}+\% 28 \mathrm{MS} \% 2 \mathrm{EACMS} \% 2 \mathrm{E}+\mathrm{ADJ} 2+22164 \% 2 \mathrm{EA}$ CMS\%2E\%29\&base=base Acordaos\&url=http://tinyurl.com/afuob5c $>$. Acesso em: 9 abr. 2018.

BRASIL. Tribunal de Contas da União. Cartilha de licenciamento ambiental. 2.ed. $4^{\mathrm{a}}$ Secretaria de Controle Externo. Brasília, 2007b. Disponível em: <http://portal2.tcu.gov.br/portal/pls/portal/docs/2059156.PDF>. Acesso em: 2 abr. 2018.

BRASIL. Tribunal de Contas da União. Relatório de Levantamento. AC 2.212-38/09-P. Plenário. Relator: Min. Aroldo Cedraz. Brasília, 23 de setembro de 2009. Disponível em: <https://contas.tcu.gov.br/juris/SvlHighLight>. Acesso em: 1 abr. 2018.

BUGALHO, Nelson R. Estudo Prévio de Impacto Ambiental. Revista de Direito Ambiental, São Paulo, v. 15, p. 18-33, jul./set. 1999.

CALDARELLI, Solange Bezerra. Pesquisa arqueológica em projetos de infra-estrutura: a opção pela Preservação. Revista do Patrimônio, n; 33: 153-174. Rio de Janeiro: IPHANInstituto do Patrimônio Histórico e Artístico Nacional, número especial sobre Arqueologia e Preservação, 2007. 
CARVALHO FILHO, José dos santos. Ação Civil Pública - Comentários por Artigo, $5^{\mathrm{a}}$ ed. Rio de Janeiro: Editora Lúmen Júris, 2005.

COELHO, Helena Carvalho. Do Direito Constitucional Ao Meio Ambiente E Desdobramentos Principiológicos à Hermenêutica (Ambiental?). Veredas do Direito, Belo Horizonte. v.11, n.21, p.53-73 • Janeiro/junho de 2014.

CUREAU, Sandra. Licenciamento Ambiental. In: GAIO, Alexandre e ABI-EÇAB, Pedro (Org.). Lei da Política Nacional do Meio Ambiente. Campo Grande: Contemplar, 2012.

DE MIO, Geisa Paganini. FERREIRA FILHO, Edward. CAMPOS, José Roberto. O inquérito civil e o termo de ajustamento de conduta para resolução de Conflitos ambientais . In Revista de Direito Ambiental. Ano 10, no 39, julho-setembro 2005, p. 92-101 apud SCALASSARA1, Lecir Maria. Conflitos ambientais: o acesso à justiça e os meios alternativos de solução de conflitos . Rev. Disc. Jur. Campo Mourão, v. 2, n. 2, jul./dez. 2006, p. 43.

FARIAS, Talden Queiroz. Aspectos gerais da política nacional do meio ambiente: comentários sobre a Lei n ${ }^{\circ}$ 6.938/81. Âmbito Jurídico, Rio Grande, IX, n. 35, dez 2006a. Disponível em: <http://www.ambito-

juridico.com.br/site/index.php?n_link=revista_artigos_leitura\&artigo_id=1544>. Acesso em 9 maio 2015.

FARIAS, Talden. Licenciamento Ambiental: aspectos teóricos e práticos. 4a ed. Belo Horizonte: Fórum, 2013.

FINK, Daniel Roberto; ALONSO JR., Hamilton; DAWALIBI, Marcelo. Aspectos Jurídicos do Licenciamento Ambiental. Rio de Janeiro: Forense Universitário, 2000.

HOFMANN, Mirian Rose. Gargalos do Licenciamento Ambiental Federal do Brasil. Consultoria Legislativa da Câmara dos Deputados. Disponível em:

<http://bd.camara.gov.br/bd/handle/bdcamara/24039>. Acesso em: 12 abr. 2016.

KRULL, André. Proporcionalidade e condicionantes na licença ambiental. Jus Navegandi, Teresina, ano 17, n. 3310, 24 jul. 2012. Disponível em: 〈http://jus.com.br/ artigos/22262〉. Acesso em: 26 jul. 2017.

MACHADO, Paulo Affonso Leme. Direito Ambiental Brasileiro. 23a ed. São Paulo: Malheiros, 2015.

MARÉS, Carlos Frederico. Introdução ao Direito Ambiental. In: LIMA, André (Org.). $O$ Direito para o Brasil Socioambiental. Porto Alegre: Sergio Antonio Fabris, 2002.

MAZZILLI, Hugo Nigro. A defesa dos interesses difusos em geral. 32ª ed, São Paulo: Saraiva, 2009.

SÁNCHEZ, Luis Enrique. Avaliação de Impacto Ambiental: conceitos e métodos. São Paulo: Oficina de Textos, 2006.

SARLET, Ingo Wolfgang; FENSTERSEIFER, Tiago. Direito Constitucional Ambiental: Constituição, Direitos Fundamentais e Proteção do Ambiente. São Paulo: Revista dos Tribunais, 2014. 
TRENNEPOHL, Curt; TRENNEPOHL, Terence. Licenciamento Ambiental. 3a ed. Niterói: Impetus, 2010.

ZAVASKI, Teori Albino. Processo Coletivo: tutela de direitos coletivos e tutela coletiva de direitos. $7^{\circ}$ ed. Ver e atual. São Paulo: Editora dos Tribunais, 2017. 